Genet. Sel. Evol. 39 (2007) 369-389

Available online at:

(C) INRA, EDP Sciences, 2007

www.gse-journal.org

DOI: $10.1051 /$ gse:2007009

Original article

\title{
A practical approach for minimising inbreeding and maximising genetic gain in dairy cattle
}

\author{
Mekonnen HAILE-MARIAM ${ }^{\mathrm{a} *}$, Phil J. BOWMAN ${ }^{\mathrm{a}}$, \\ Mike E. GODDARD ${ }^{\mathrm{a}, \mathrm{b}}$ \\ ${ }^{a}$ Primary Industries Research Victoria, Attwood Centre, 475 Mickleham Road, Attwood, \\ Vic 3049, Australia \\ ${ }^{\mathrm{b}}$ Faculty of Land and Food Resources, University of Melbourne, Parkville 3010, Australia
}

(Received 15 September 2006; accepted 13 February 2007)

\begin{abstract}
A method that predicts the genetic composition and inbreeding $(\mathrm{F})$ of the future dairy cow population using information on the current cow population, semen use and progeny test bulls is described. This is combined with information on genetic merit of bulls to compare bull selection methods that minimise $\mathrm{F}$ and maximise breeding value for profit (called APR in Australia). The genetic composition of the future cow population of Australian HolsteinFriesian (HF) and Jersey up to 6 years into the future was predicted. F in Australian HF and Jersey breeds is likely to increase by about 0.002 and 0.003 per year between 2002 and 2008, respectively. A comparison of bull selection methods showed that a method that selects the best bull from all available bulls for each current or future cow, based on its calf's APR minus F depression, is better than bull selection methods based on APR alone, APR adjusted for mean F of prospective progeny after random mating and mean APR adjusted for the relationship between the selected bulls. This method reduced $\mathrm{F}$ of prospective progeny by about a third to a half compared to the other methods when bulls are mated to current and future cows that will be available 5 to 6 years from now. The method also reduced the relationship between the bulls selected to nearly the same extent as the method that is aimed at maximising genetic gain adjusted for the relationship between bulls. The method achieves this because cows with different pedigree exist in the population and the method selects relatively unrelated bulls to mate to these different cows. Selecting the best bull for each current or future cow so that the calf's genetic merit minus $\mathrm{F}$ depression is maximised can slow the rate of increase in $\mathrm{F}$ in the population.
\end{abstract}

inbreeding / dairy cattle / bull selection methods / genetic merit

\footnotetext{
*Corresponding author: Mekonnen.HaileMariam@dpi.vic.gov.au
} 


\section{INTRODUCTION}

The use of an animal model for calculating estimated breeding value (EBV) has led to increased probability of selecting related animals $[14,18]$ and advances in reproductive technology have increased the reproductive capacity of individuals leading to increased use of a few influential animals [14]. Both circumstances increase the probability of inbreeding $(\mathrm{F})$. $\mathrm{F}$ has a detrimental effect on many traits that affect the profitability of dairy cows. For example, over the lifetime of a registered Holstein cow the net economic loss per $1 \%$ of F has been estimated at US\$22 (manufacturing milk) to \$24 (fluid milk) [11]. There is concern among dairy farmers and others that the rate of $\mathrm{F}$ may be higher than is desirable. Many studies [2, 5, 8,9,12,13,17] have calculated the rate of $F$ in the past but it is the rate of $F$ in the future that is of greatest concern and that can be altered by breeding decisions. The first aim of this paper was to demonstrate a method to predict the rate of $\mathrm{F}$ in the immediate future and to apply it to Australian Holstein and Jersey breeds.

Numerous strategies to minimise short and long-term $\mathrm{F}$ have been proposed $[4,7,8,10,13,15,16,18]$. Other methods that aim to maintain diversity without paying direct attention to $\mathrm{F}$ are also available [6]. An important distinction is between short-term F (i.e. in the next generation), which depends on the relationship between mates, and long-term $\mathrm{F}$ which depends on the average relationship among all selected parents. The methods of Wray and Goddard [18] and Meuwissen [10] are both aimed at maximising the benefit from additive genetic gain while minimising the loss from long-term F. Meuwissen [10] does this by adopting a maximum acceptable rate of $\mathrm{F}$ while Wray and Goddard [18] maximise an objective that is the value of additive genetic gain less the economic loss from $\mathrm{F}$, but the methods lead to the same selection decisions if corresponding values of maximum rate of $\mathrm{F}$ and cost of $\mathrm{F}$ are used.

However, long-term F, based on the average relationship among bulls selected, may not be relevant to an AI stud competing in an open cattle population. Firstly, it may not predict long-term F because bulls from other AI studs and other countries will contribute to the gene pool. Secondly long-term F will not be a cost to the individual AI stud but to the whole population. Therefore we should ask "What selection policy would maximise profit for an individual dairy farmer or AI stud and what are the consequences of this policy for long and short-term F?"

The logical selection criterion for a dairy farmer choosing a mate for an individual cow is the estimated breeding value of the resulting calf minus the cost of its F [7]. If dairy farmers select on this criterion then, when an AI company is selecting young bulls to progeny test, the potential value of these 
bulls depends, in part, on how closely these bulls will be related to the cow population in 5 years time when the bulls have completed the progeny test and could be widely used. When bull sires are being selected, the young bulls produced will not be widely used for 6 years and so it is the cow population 6 years in the future that is relevant. The future cow population can be predicted by combining pedigree data on the current cow population with data on semen use and the pedigrees of progeny test bulls that are expected to graduate in the coming 4 years. This prediction of the future cow population also generates a prediction of future $\mathrm{F}$.

The second purpose of the paper was to compare several bull selection methods for their effect on additive genetic merit, short-term and long-term F. We will also illustrate how these methods can be applied to the selection of young bulls and bull sires by taking account of the cow population that is expected to exist when the bulls or their sons are widely used. The bull selection method proposed by Goddard and Smith [7] is compared to methods proposed by Wray and Goddard [18] and to selection on genetic merit alone, for effect on both short and long-term F. Dairy farmers may either use selected bulls randomly across the cow herd or select a bull for mating to each cow. In the former case, it is the average relationship of the bull to the cow herd that is important while in the latter method it is the relationship of the bull to a specific cow that is relevant. Both methods of selection were investigated.

In the first part of this paper we predict the future cow population based on the current bull and cow population and current breeding practices. In the second part we used the predicted cow population when comparing the bull selection methods by combining the information on genetic merit with the information on $\mathrm{F}$ of prospective calves.

\section{MATERIALS AND METHODS}

Calving and pedigree data on Jersey and Holstein-Friesian breeds up to December 2004 and mating data up to March 2004 were provided by the Australian Dairy Herd Improvement Scheme (ADHIS) [1]. The historical pedigree data extended to the 1940s but the completeness was generally poor until the 1980s. For animals born after 1990 the complete generation equivalent calculated using the software of Boichard [3] varied from 3.4 (1990) to 5.7 (2004). The pedigree and calving data were used to predict the genetic composition of the cow herd in 2005 to 2009 based on the cow and bull populations that were available up to 2004. Genetic evaluation which is based on the Australian economic index called Australian Profit Ranking (APR) released in February 2004 
was combined with the information on the genetic composition of the HF cow herd to compare bull selection methods.

\subsection{Prediction of the future cow population and $F$}

\subsubsection{Generating the future cow population}

A single replicate stochastic simulation was used to generate the future cow population based on the current breeding practices in Australian dairy cattle. The stochastic decisions made in this study average out effectively and only a single replicate is adequate to predict the cow population. In the simulation the following four populations are updated each year - cows 2-12 years old, heifers $0-1$ year old, proven bulls and young bulls $1-5$ years old. The proven bull population was based on semen used in the 2003/2004 mating (mating seasons run from April to the following March). Cows and proven bulls were included if their two parents were known, but young progeny test bulls were included only if they had four known grandparents.

Each year the cow herd was generated by moving all cows to the next age group after randomly culling a proportion that varied from 5\% (young cows) to $60 \%$ (cows over 10 years of age). "Hypothetical" calves were generated by mating each cow to one of the bulls. Bulls were used in proportion to their frequency in matings in 2003/04. The proportion of cows mated to bulls born before 1999 decreased each year after 2004 while the proportion of cows that were mated to bulls born after 1999 (i.e. young bulls in a progeny testing scheme) increased. Each year a new cohort of young bulls will complete their progeny test and some will be widely used. Since we do not know which of the young bulls will be widely used after progeny testing, they were all used equally, starting in the year when their progeny test will be completed, and were used for 2 consecutive years. Cows were mated to these bulls at random except that parent-offspring and sib matings were avoided.

For generating progeny, the male and female population in 2001 was used as a starting point. Thus, starting in 2001 if the last record on a cow was a mating, then a hypothetical calf with the appropriate pedigree was generated 282 days later. If the last record was a calving, then a mating was generated 90 days later using semen chosen at random from the bull population with each bull used according to the proportion of his semen in the total for that year. Mature cows in the current population were considered for mating if they were below 12 years of age. The process described above for generating the next year's population was applied starting in 2002 to generate some hypothetical calves to 
maintain total herd numbers approximately constant when these hypothetical calves were added to the real calves already recorded. Cows that are not culled were moved to the next age class assuming that they mate and calve every year at the same date until they reached 12-years of age. This gradually replaced the "real" cows in the starting population by "hypothetical" cows that were born two years earlier.

\subsubsection{Estimation of $F$}

All "hypothetically" generated animals were added to the pedigree data provided by ADHIS. F coefficients of all the animals in the pedigree were calculated using the software program of Boichard [3].

\subsubsection{Validation of the method}

The following validations were undertaken using retrospective data. First, HF cows $(n=159642)$ that produced progeny in 2000 were hypothetically randomly mated to 1149 HF bulls whose semen was used in 1999 and the mean F of their "progeny" was calculated. The number of progeny generated from each bull was determined by their frequency of use in the mating data of 1999. The F of the "hypothetical" calves was compared to that of the real calves born in 2000. Secondly, the proportion of semen of the most influential bulls used in 1999 was compared to the proportion of progeny born to these bulls in 2000 and the simple correlation between semen use and number of progeny was calculated. Thirdly, 107 (a random sample from 450) progeny test bulls born in 1996 which were assumed to graduate in 2001 were hypothetically mated to about $10 \%$ of the active cows of 2001 (20 224 cows) equally and the mean F of their "progeny" was calculated. Each bull was mated equally and randomly to mimic the way young bulls born after 1999 were used to generate progeny in this study. The mean $\mathrm{F}$ of the prospective progeny from these bulls was compared to that of animals born in 2002. Fourthly, mean F of progeny actually born and hypothetically generated between 2002 and 2004 were compared.

\subsection{Use of the predicted cow population to select bulls}

Three cow populations, namely active cows of 2004 (i.e. current), 2007 and 2009 (future) were considered for mating to proven and young bulls in order 
Table I. Bull selection and mating methods.

\begin{tabular}{lllll}
\hline Method & $\begin{array}{l}\text { Bull selection } \\
\text { criterion }\end{array}$ & Mating & $\begin{array}{l}\text { No. of } \\
\text { bulls }\end{array}$ & $\begin{array}{l}\text { Max. prop. of } \\
\text { cows to a bull }\end{array}$ \\
\hline APR alone & $1 / 2 \mathrm{APR}$ & Random & 10 & 0.1 \\
APR adj. for $\bar{F}$ & $1 / 2 \mathrm{APR}-\mathrm{b} \bar{F}$ & Random & 10 & 0.1 \\
APR adj. for $\mathrm{F}$ & $1 / 2 \mathrm{w}^{\prime} \mathrm{APR}-\mathrm{bw}^{\prime} \mathrm{F}$ & $\begin{array}{l}\text { Individual } \\
\text { Variable }\end{array}$ & 0.1 \\
APR non-random & $1 / 2 \mathrm{APR}$ & Individual & 10 & 0.1 \\
W\&G method & $\mathrm{w}^{\prime} 1 / 2 \mathrm{APR}-1 / 8 \mathrm{w}^{\prime} \mathbf{R} \mathrm{w}$ & Random & Variable & Variable \\
\hline
\end{tabular}

$\mathrm{R}$ is genetic relationship between the bulls; $\mathrm{b}$ is cost of $\mathrm{F}$; $\mathrm{w}$ is proportion of use of bulls.

to compare different bull selection methods. The following selection decisions were considered:

(1) Selection of bulls to breed cows, i.e. 117 current proven bulls with the highest APR based on February 2004 evaluation were mated to cows of 2004. The mean APR of these bulls was 111.6 with a standard deviation of 12.9.

(2) Selection of young bulls to breed future cows, i.e. 140 current yearling bulls (those born in 2002) were mated to the cow population in 4 years time (cows of 2007). These are progeny test (PT) bulls selected on their pedigree in 2003 and who will graduate in 2007. The mean APR of these bulls was 90.3 with standard deviation of 23.7 .

(3) Selection of bulls to breed bulls, i.e. current proven bulls mated to the future cow population (as example cows of 2009 were selected).

Bulls in each category were mated to about $3 \%$ ( 14 000 cows) of the active cows (a random sample of cows) that are available that year. The F of prospective progeny from the proposed matings were calculated using [3]. The number of cows used to determine $\mathrm{F}$ of a bull's prospective progeny was assumed adequate since VanRaden and Smith [13] have shown prospective mating of a bull to 500 cows to be sufficient to characterise a bull.

\subsubsection{Description of the bull selection methods}

The following bull selection methods were compared (Tab. I):

(1) Bulls selected on APR alone - the best 10 bulls selected based on their APR are randomly mated to the target cow population (APR alone).

(2) Bulls selected on APR adjusted for mean cost of F depression of their prospective progeny when they are randomly mated - the top 10 bulls based on their $(1 / 2 \mathrm{APR}-\mathrm{b} \bar{F})$ where $\bar{F}$ is the mean $\mathrm{F}$ of a bull's progeny and $\mathrm{b}$ is 
the rate of F depression in APR units (\$) per unit of F. Cost of F depression was calculated (see Sect. 2.2.3) to be 3 or 9 APR per $1 \%$ F. This method is called APR adj. for $\bar{F}$.

(3) Bulls selected on APR adjusted for F of their prospective progeny when mated to a specific cow. In this method, a bull is selected for each cow with maximum APR adjusted for $\mathrm{F}$ depression of prospective progeny selected $(1 / 2 \mathrm{APR}-\mathrm{bF})$ with the restriction that a single bull will not mate to over $10 \%$ of the cows. This method is called APR adj. for F.

(4) The ten bulls selected in method 1 above are selectively mated to the cow herd with the criterion that a cow is assigned to a bull that maximises APR adjusted for $\mathrm{F}$ of prospective progeny (as method 3). A bull is mated to $10 \%$ of the cows (APR non-random).

(5) Amongst the three bull selection methods proposed by the Wray and Goddard [18] strategy, 3 where a variable (optimum) number of bulls are selected based on their relationship matrix $(\mathbf{R})$ and their APR and each are mated to a variable number of cows (proportion of use of semen from bull $i=\mathrm{w}_{i}$ ). Both number of bulls and number of matings were chosen to optimise $\left(1 / 2 w^{\prime}\right.$ APR $\left.-1 / 8 b w^{\prime} \mathbf{R} w\right)$. The details are given in [18]. The bulls that are selected using this method are randomly mated to the cow population. This is called the W\&G method.

\subsubsection{Criteria for comparing the bull selection methods}

The following criteria were used to compare bull selection methods:

(1) Mean half APR of the selected bulls weighted by their use (w) (i.e. proportion of mating) $1 / 2 \mathrm{w}^{\prime} \overline{A P R}$;

(2) Mean $\mathrm{F}$ of the prospective progeny of the bulls weighted by their use $\left(\mathrm{w}^{\prime} \bar{F}\right)$;

(3) Mean $\mathrm{R}$ among the selected bulls weighted by their use ( $\left.\mathrm{w}^{\prime} \bar{R} \mathrm{w}\right)$;

(4) Mean half APR adjusted for F of the prospective progeny of the selected bulls weighted by their use. The adjustment was made by subtracting the product of cost of $\mathrm{F}$ and $\mathrm{F}\left(1 / 2 \mathrm{w}^{\prime} \mathrm{APR}-\mathrm{bw}^{\prime} \bar{F}\right)$;

(5) Mean half APR adjusted for $\mathrm{R}$ among the bulls. The adjustment was made by subtracting the product of cost of $F$ and $1 / 8$ of the average $R$ $\left(1 / 2 \mathrm{w}^{\prime} \overline{A P R}-1 / 8 \mathrm{bw}^{\prime} \mathbf{R} \mathrm{w}\right)$.

\subsubsection{Cost of $\mathbf{F}$}

The cost of $\mathrm{F}$ depression is calculated in two ways. First, estimates of $\mathrm{F}$ depression by Man [9] and economic weights used to derive the Australian 
Profit Ranking (APR) were combined [1] to estimate the monetary value of $\mathrm{F}$ depression which was found to be equivalent to about 3.1 APR per $1 \% \mathrm{~F}$. Secondly, Smith et al. [11] calculated the net economic loss over the lifetime of a cow to be US\$24 in registered cattle producing liquid milk (maximum F depression). Assuming that the difference in currencies is compensated for by the difference in milk price between the two countries and that the lifetime of HF cows in the USA is about 2.8 lactations, the cost of $1 \% \mathrm{~F}$ was equivalent to about 8.5 APR. Thus, the different bull selection methods were compared assuming that the cost of $\mathrm{F}$ is 3 or 9 APR per $1 \% \mathrm{~F}$.

\section{RESULTS}

\subsection{Predicting the future cow population}

\subsubsection{Current and predicted future cows}

About $573000 \mathrm{HF}$ and 82000 Jersey cows were available in 2001 for calving based on lactation, pedigree, mating and culling data. In 2002 to 2004 both hypothetical and real calves were born. In 2002 in both breeds about 40 to $44 \%$ of the calves were already recorded and the rest were generated from the hypothetical and real matings. This was due to delays in the flow of birth and calving data to ADHIS. Most cows are registered as they calve and start milking but some calves are registered as they are born.

\subsubsection{Past, current and future $\mathbf{F}$}

The mean $\mathrm{F}$ of animals by year of birth is shown in Figure 1 for HF and Jersey. In HF, F increased only by about 0.0003 per year during 1979 to 1991 . From 1992 to 2001, F increased by 0.001 per year and from 2002 to 2008 it is predicted to increase by about 0.0016 per year. In Jersey there was a small increase in $\mathrm{F}$ between 1979 and 1987 followed by a small decrease up to 1990 (Fig. 1). Between 1990 and 1995, mean F increased by about 0.001 per year. Starting in 1996 mean F has increased by about 0.002 per year up to 2001. The estimates on the available animals and the prediction show that $\mathrm{F}$ will likely increase by about 0.003 per year between 2002 and 2008 .

The maximum difference in $\mathrm{F}$ of animals when cows with at least two known parents (sire and dam) are used and at least four known grand parents was only 0.005 in HF and 0.009 in Jersey. The rate of increase in F was not affected by pedigree completeness since cows with both parents known approached that 


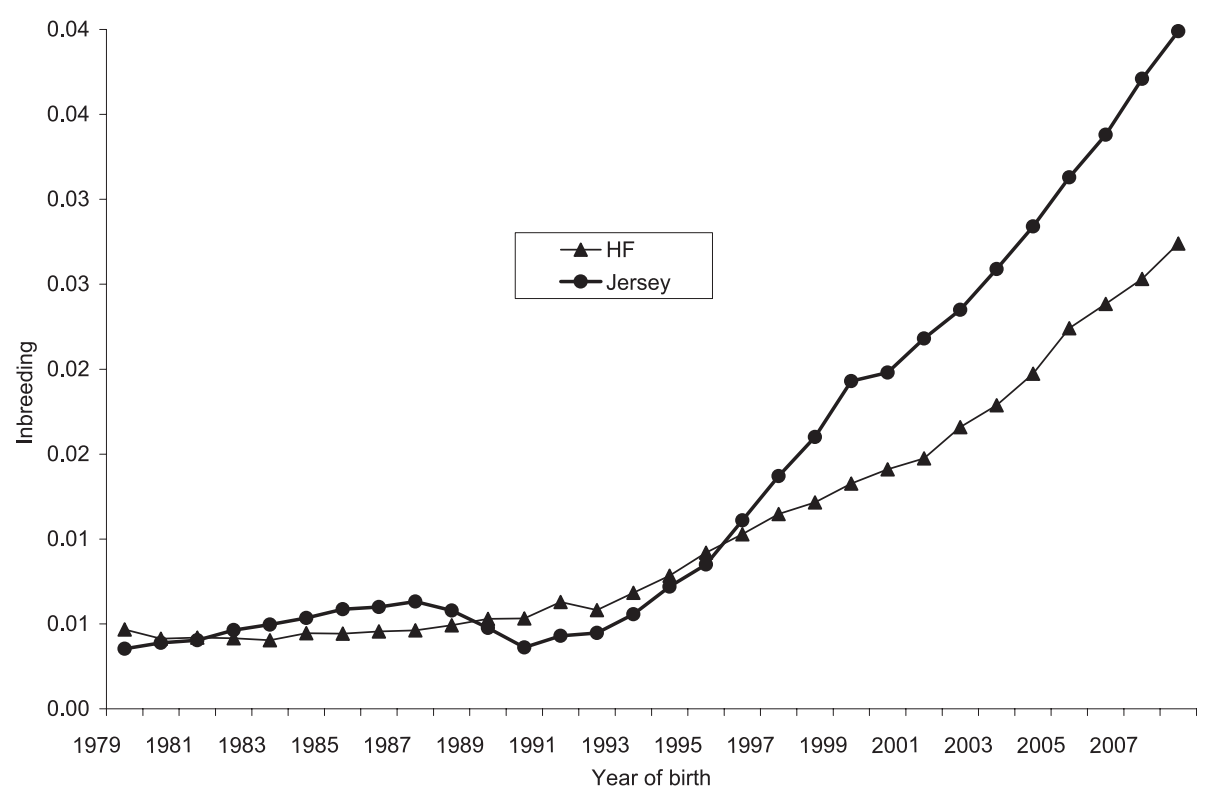

Figure 1. Past, current and future inbreeding in Australian Holstein-Friesian and Jersey cattle.

of 4 grand parents known about 3 to 4 years later. For example, the F of HF animals with at least 4 known grand parents was 0.0167 in 1999 and animals with at least two known parents in 2002 reached 0.0166 . This difference is similar to the difference in mean $\mathrm{F}$ between male and female animals (result not shown).

\subsubsection{Validation of the method}

When HF bulls whose semen was used in 1999 were randomly mated to active cows of 1999 the mean $\mathrm{F}$ of their progeny was 0.0149 . This is close to the mean F of HF animals born in 2000 (Fig. 1) which was 0.0141. The simple correlation between frequency of semen use and frequency of progeny born from these bulls was 0.96 .

The mean $\mathrm{F}$ of prospective progeny of 107 progeny test bulls born in 1996 that were randomly mated (hypothetically) to the active cows of 2001 (year of their graduation) was 0.0176 . This is reasonably close to the mean $\mathrm{F}$ of animals born in 2002 which was 0.0166 (Fig. 1). This confirms that the decision to use progeny test bulls born 5 years earlier randomly and equally on the cow population that will be available when they graduate, is valid. 


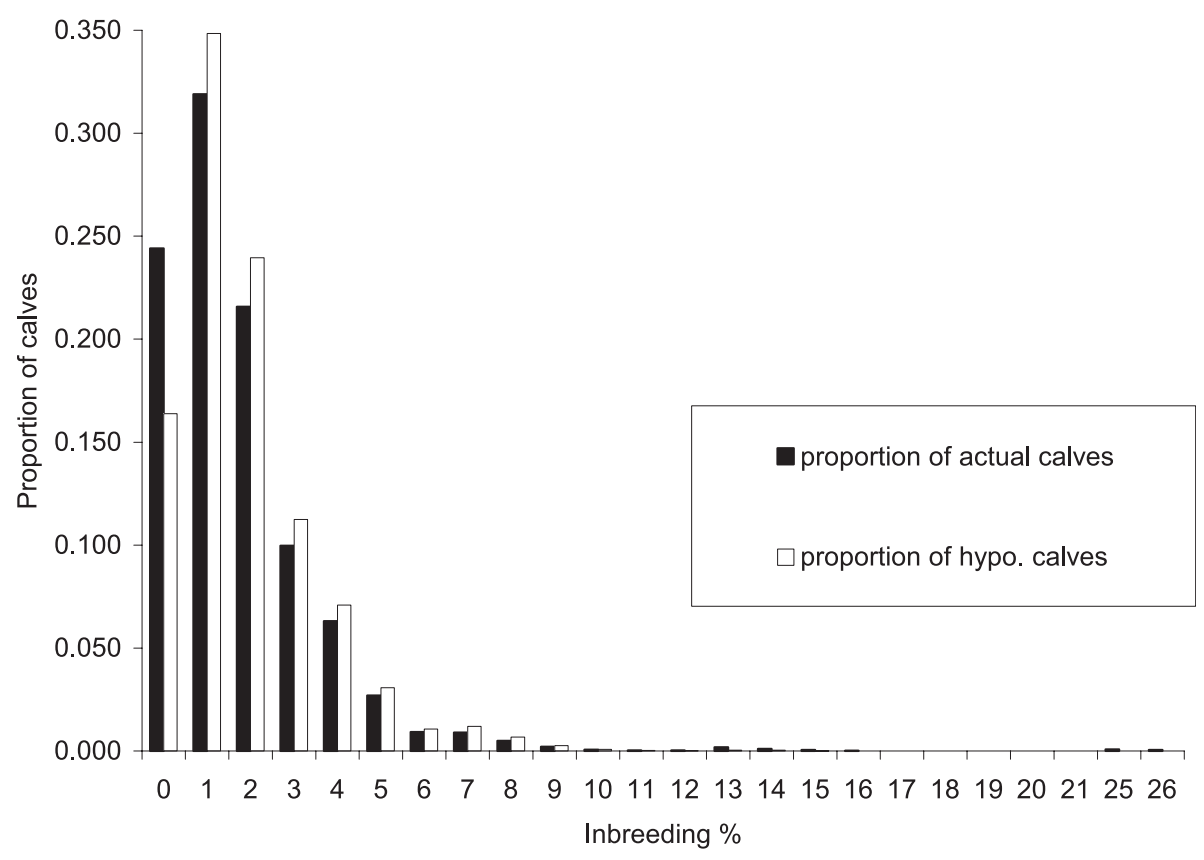

Figure 2. Proportion of actual and hypothetical calves born between 2002 and 2004 by their inbreeding in Holstein-Friesians.

Table II. Mean F of progeny actually born and hypothetical generated in the years when both actual and hypothetical calves were born (2002-2004).

\begin{tabular}{lcccccc}
\hline Breed & \multicolumn{2}{c}{2002} & \multicolumn{2}{c}{2003} & \multicolumn{2}{c}{2004} \\
\hline & Actual & Hypo. & Actual & Hypo. & Actual & Hypo. \\
Jersey & 0.0252 & 0.0225 & 0.0278 & 0.0255 & 0.0290 & 0.0283 \\
HF & 0.0162 & 0.0168 & 0.0177 & 0.0180 & 0.0188 & 0.0199 \\
\hline
\end{tabular}

The mean $\mathrm{F}$ of animals that were already born was similar to that of hypothetically generated animals (Tab. II) in both breeds. Figure 2 shows the distribution of $\mathrm{F}$ in actual and hypothetical calves born between 2002 and 2004 for $\mathrm{HF}$ calves. The mean $\mathrm{F}$ of calves that were actually born is reasonably similar to those that were hypothetically generated. There were more actual calves with zero $\mathrm{F}$ than hypothetical calves but in the other categories differences were small. In the case of Jersey the proportion of hypothetical and actual calves had a similar distribution of $\mathrm{F}$ values (Fig. 3). This shows that Australian dairy farmers make little effort to avoid inbred matings other than to avoid sire-daughter and brother-sister matings. 


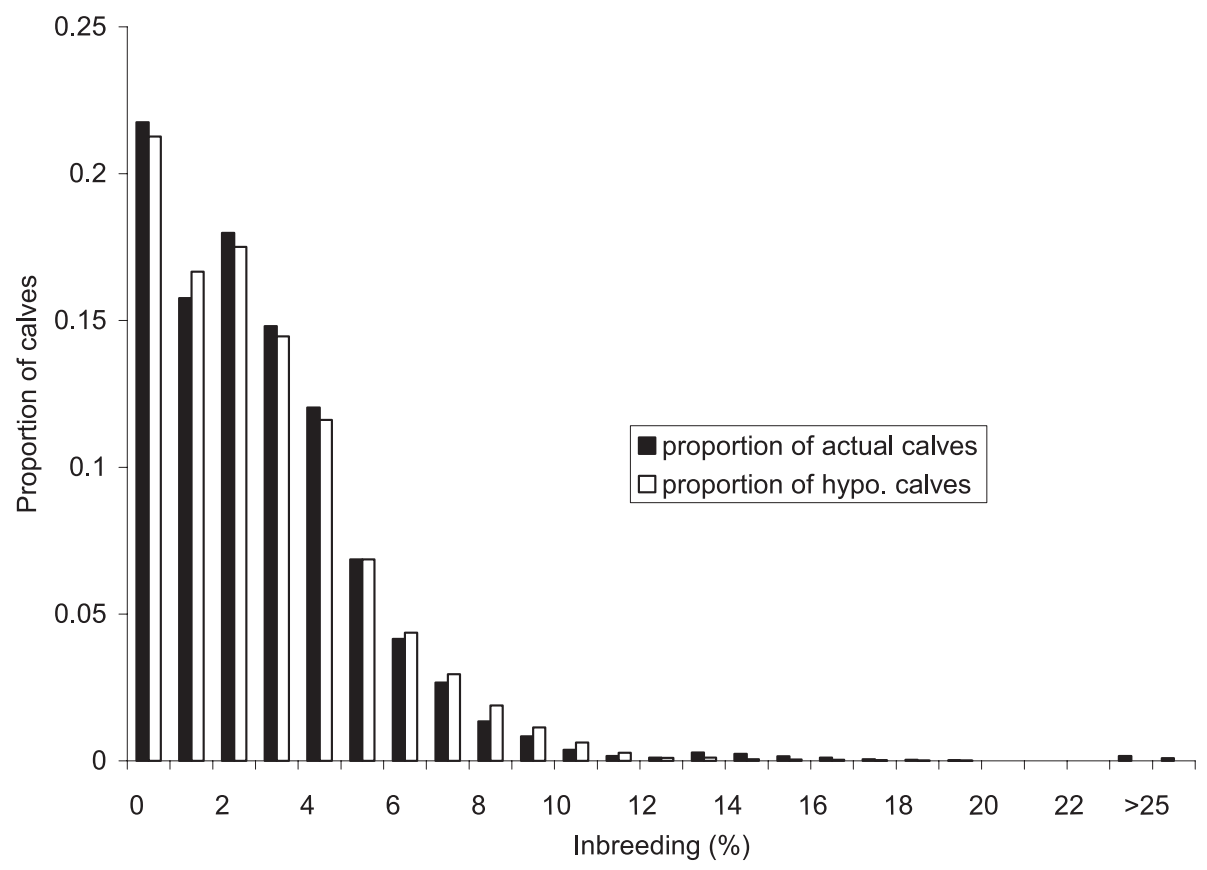

Figure 3. Proportion of actual and hypothetical calves born between 2002 and 2004 by their inbreeding in Jerseys.

\subsection{Comparison of bull selection methods}

The different bull selection and mating methods are described in Table I.

\subsubsection{Selecting proven bulls to mate current cows}

Table III shows the effect of selecting proven bulls to mate current cows when the cost of $1 \%$ of $\mathrm{F}$ is assumed to be 3 and 9 APR. The three methods that took account of the $\mathrm{F}$ of the calves born reduced the $\mathrm{F}$ of these calves substantially (by about half or 1\%). When 10 bulls were selected for random mating, based on their average relationship to the cow population (1/2APR$\mathrm{b} \bar{F})$, their mean APR was reduced but their APR adjusted for $\bar{F}$ was higher than that of the bulls selected on APR alone. However, selecting bulls for random mating in this way leads to a group of 10 bulls that are more closely related to each other than selecting simply on APR alone when cost of $\mathrm{F}=9 \mathrm{APR} / \% \mathrm{~F}$. On the contrary, if the best bull is selected for mating to each individual cow, the mean APR is higher and the mean F is lower than when bulls are selected for random mating. More surprisingly, the mean relatedness of the bulls is 
quite low so that the mean APR adjusted for $\bar{R}$ is not much worse than that of the W\&G method. Presumably this is because, by selecting different bulls for mating to different cows, a diverse group of bulls is selected with low average relationship to each other. Thus, this strategy not only results in the lowest short-term F, but also reasonably low long-term F.

When bulls are selected on APR alone, APR adjusted for $\bar{F}$ and APR non random mating, each bull is used equally. Weighing their use by their genetic merit gave similar results to that of equal use because any gain from increased use of high APR bulls was compromised by the increased cost of F. For example, when bulls are selected on APR adjusted for $\bar{F}$, genetic merit adjusted for mean $\mathrm{F}(1 / 2 \mathrm{APR}-\mathrm{b} \bar{F})$ of the progeny increased from 64.2 (Tab. III) to 64.5 (when use was proportional to APR) when cost of $1 \% \mathrm{~F}$ was 3 APR units. The increase was from 53.9 (equal use) to 54.2 (use weighted by genetic merit) when cost of $1 \% \mathrm{~F}$ was assumed to be 9 APR units.

The method that selects the best bull from all bulls for each cow so that the calf's APR adjusted for $F$ is the highest reduces $F$ by about $2 / 3$ and selects 19 bulls. The $\mathrm{W} \& \mathrm{G}$ method $\left(1 / 2 \mathrm{w}^{\prime} \mathrm{APR}-\mathrm{w}^{\prime} \mathrm{Rw}\right)$, which optimises the proportional contribution of each bull, selected 34 bulls that are unequally used, and achieved a lower $\bar{R}$ and a higher APR adjusted for $\bar{R}$. Thus, if this was a closed population, the W\&G method would result in lower long-term $F$ than simply selecting the 10 bulls with the highest APR. However, the W\&G method does not reduce the $\mathrm{F}$ of the calves born by mating these bulls randomly to the current cow population. That is, the W\&G method has no effect on short-term F. If the bulls selected by the W\&G method were non-randomly mated to cows, a lower $\mathrm{F}$ in the calves could be achieved. In this particular example since 17 of the 19 bulls selected by APR adjusted for F (results not shown) were in the 34 bulls selected by the W\&G method, this method will only be slightly inferior to APR adj. for F.

\subsubsection{Selecting young bulls to mate cows that will be available at their graduation}

Table IV shows the effect of selecting young bulls based on their relation to cows that will be available at the time they graduate when the cost of $1 \%$ of $\mathrm{F}$ is assumed to be 3 or 9 APR. The performance of the different bull selection methods is similar to that observed when proven bulls are mated to current cows. The mean APR adjusted for F is less than in the first situation mainly because the F of the cows has increased and the bulls used are not as good as the proven bulls. Again the W\&G method results in the lowest relationship among 
Table III. Selecting proven bulls to mate to current cows on mean F and APR of prospective progeny.

\begin{tabular}{llllllll}
\hline Bull selection method & No. & Prop. of use & \multicolumn{5}{c}{ Criteria measured in prospective progeny or in the bulls } \\
\hline Cost of 1\% F = 3 APR & & & $1 / 2 \overline{A P R}$ & $\bar{F}$ & $1 / 2 \mathrm{APR}-\mathrm{b} \bar{F}$ & $\bar{R}$ & $1 / 2 \mathrm{w}^{\prime} \mathrm{APR}-1 / 8 \mathrm{w}^{\prime} \bar{R} \mathrm{w}$ \\
APR alone & 10 & 0.1 & 70.8 & 0.024 & 63.7 & 0.126 & 66.1 \\
APR adj. for $\bar{F}$ & 10 & 0.1 & 70.3 & 0.020 & 64.2 & 0.126 & 65.6 \\
APR adj. for F & 17 & $0.0001-0.1$ & 70.5 & 0.011 & 67.2 & 0.117 & 66.9 \\
APR non-random & 10 & 0.1 & 70.8 & 0.013 & 66.8 & 0.126 & 66.1 \\
W\&G method & 14 & $0.02-0.23$ & 73.1 & 0.024 & 65.7 & 0.150 & 67.4 \\
Cost of 1\% F =9 APR & & & & & & & \\
APR alone & 10 & 0.1 & 70.8 & 0.024 & 49.4 & 0.126 & 56.7 \\
APR adj. for $\bar{F}$ & 10 & 0.1 & 65.1 & 0.012 & 53.9 & 0.150 & 48.2 \\
APR adj. for F & 19 & $0.0001-0.1$ & 69.0 & 0.008 & 62.1 & 0.108 & 57.6 \\
APR non-random & 10 & 0.1 & 70.8 & 0.012 & 59.6 & 0.126 & 56.7 \\
W\&G method & 34 & $0.002-0.11$ & 68.7 & 0.022 & 48.8 & 0.079 & 59.8 \\
\hline
\end{tabular}


the bulls but the F of the calves is as high as selecting on APR alone. Even when bulls are selected for random mating but accounting for the average $\mathrm{F}$ of their calves, there is only a small decrease in F. But if the best bull is chosen for each individual cow, then the F is reduced by about $1 \%$ (Tab. IV) and the relationship among the bulls is reduced although not as much as the W\&G method.

Selecting 10 bulls for random mating, based on their average relationship to the cow population $(1 / 2 \mathrm{APR}-\mathrm{b} \bar{F})$, does not reduce $\mathrm{F}$ in the progeny as much as the case of selecting proven bulls to mate current cows.

\subsubsection{Selecting proven bulls to produce future bulls}

Table V shows the effect of selecting proven bulls based on their relationship to cows that will be available at the time when their sons graduate. The bulls considered are those which were mated to current cows in the first situation (Tab. III) but here they are mated to cows that will be available when their sons graduate in 5 years time. In reality it is the sons of these bulls that will be mated to the cows in 2009, so both the effect of the selection on the APR and on the F of the calves will be halved but the comparisons between selection methods are still valid. The comparison between the selection strategies is similar to that observed in the other two scenarios (Tabs. III and IV). If cost of F is assumed to be 9 APR per $1 \%, \mathrm{~F}$ can be minimised by selecting 22 bulls based on APR adj. for $\mathrm{F}$ of their prospective progeny.

\section{DISCUSSION}

The low rate of increase in F (0.0003 per year) between 1979 and 1991 in HF is probably because Australian cows were being mated to distantly related bulls of North American ancestry [9]. The importation of North American semen started towards the end of the 1970s first from Canada and then the USA (Les Jones, pers. comm.). The small decline in the rate of $\mathrm{F}$ in Jersey that was observed between 1987 and 1990 (Fig. 1) is probably due to mating a large proportion of the Australian Jersey cows to US bulls which started towards the mid 1980s. The degree of infusion of North American Jersey was much quicker and more intense than in HF which resulted in a small initial decline and then accelerated increase in F. The more accelerated increase in $\bar{F}$ in Jersey than in HF is mainly related to the number of bulls progeny tested, the size of the cow population and recent $\mathrm{F}$ level of the population (Fig. 1). This was 
Table IV. Selecting young test bulls to mate future cows (cows that will be available when they graduate) on F and APR of prospective progeny.

\begin{tabular}{llllllll}
\hline Bull selection method & No. & Prop. of use & \multicolumn{5}{l}{ Criteria measured in prospective progeny or in the bulls } \\
\hline Cost of 1\% F = 3 APR & & & $1 / 2 \overline{A P R}$ & $\bar{F}$ & $1 / 2 \mathrm{APR}-\mathrm{b} \bar{F}$ & $\bar{R}$ & $1 / 2 \mathrm{w}^{\prime} \mathrm{APR}^{\prime}-1 / 8 \mathrm{w}^{\prime} \bar{R} \mathrm{w}$ \\
APR alone & 10 & 0.1 & 68.8 & 0.031 & 59.5 & 0.169 & 62.5 \\
APR adj. for $\bar{F}$ & 10 & 0.1 & 68.8 & 0.031 & 59.5 & 0.169 & 62.5 \\
APR adj. for F & 16 & $0.0003-0.1$ & 68.5 & 0.021 & 62.2 & 0.158 & 62.6 \\
APR non-random & 10 & 0.1 & 68.8 & 0.021 & 62.3 & 0.171 & 62.4 \\
W\&G method & 12 & $0.02-0.2$ & 70.4 & 0.028 & 61.8 & 0.181 & 63.6 \\
Cost of 1\% F = APR & & & & & & & \\
APR alone & 10 & 0.1 & 68.8 & 0.031 & 41.0 & 0.169 & 49.8 \\
APR adj. for $\bar{F}$ & 10 & 0.1 & 67.5 & 0.028 & 42.2 & 0.166 & 48.8 \\
APR adj. for F & 28 & $0.0001-0.1$ & 67.4 & 0.018 & 51.0 & 0.143 & 51.3 \\
APR non-random & 10 & 0.1 & 68.8 & 0.020 & 50.1 & 0.171 & 49.6 \\
W\&G method & 30 & $0.002-0.11$ & 66.0 & 0.030 & 38.7 & 0.113 & 53.3 \\
\hline
\end{tabular}


Table V. Selecting bull sires to mate future cows on F and APR of prospective progeny.

\begin{tabular}{llllllll}
\hline Bull selection method & No. & Prop. of use & \multicolumn{5}{c}{ Criteria measured in prospective progeny or in the bulls } \\
\hline Cost of 1\% F = 3 APR & & & $1 / 2 \overline{A P R}$ & $\bar{F}$ & $1 / 2 \mathrm{APR}-\mathrm{b} \bar{F}$ & $\bar{R}$ & $1 / 2 \mathrm{w}^{\prime} \mathrm{APR}-1 / 8 \mathrm{w}^{\prime} \bar{R} \mathrm{w}$ \\
APR alone & 10 & 0.1 & 70.8 & 0.026 & 62.9 & 0.126 & 66.1 \\
APR adj. for $\bar{F}$ & 10 & 0.1 & 70.3 & 0.022 & 63.6 & 0.126 & 65.6 \\
APR adj. for F & 17 & $0.0001-0.1$ & 70.3 & 0.012 & 66.6 & 0.116 & 66.5 \\
APR non-random & 10 & 0.1 & 70.8 & 0.016 & 66.0 & 0.126 & 66.1 \\
W\&G method & 14 & $0.003-0.23$ & 73.1 & 0.027 & 64.8 & 0.150 & 67.4 \\
Cost of 1\% F =9 APR & & & & & & & \\
APR alone & 10 & 0.1 & 70.8 & 0.026 & 47.0 & 0.126 & 56.7 \\
APR adj. for $\bar{F}$ & 10 & 0.1 & 66.6 & 0.015 & 52.8 & 0.129 & 52.0 \\
APR adj. for F & 22 & $0.0001-0.1$ & 68.6 & 0.009 & 60.6 & 0.111 & 56.9 \\
APR non-random & 10 & 0.1 & 70.8 & 0.015 & 57.5 & 0.126 & 56.7 \\
W\&G method & 34 & $0.002-0.11$ & 68.7 & 0.025 & 46.5 & 0.079 & 59.8 \\
\hline
\end{tabular}


in agreement to Weigel and Lin [15] who observed that $\mathrm{F}$ and rate of increase in $\mathrm{F}$ are higher in Jersey than in HF in the USA.

Our prediction of the cow population up to 5 years into the future relies on assumptions about bull selection and mating. We used four tests to validate these assumptions by applying the prediction method and comparing the predicted results with actual results. In all cases the agreement was reasonably good.

The assumption that sire-progeny and sib matings are avoided when generating hypothetical progeny agrees with the observed $\mathrm{F}$ of animals in the population. In the actual progeny born between 2002 and 2004, only $0.08 \%$ of the HF calves had an $\mathrm{F}$ of 0.25 possibly as a result of sire-progeny or full-sib mating. This proportion was slightly higher at $0.16 \%$ in Jersey. Some herd improvement centres provide mate allocation services to dairy farmers in Australia (Daniel Abernethy, pers. comm.) that recommend restricting $\mathrm{F}$ of progeny to below 0.0625 . However, these services are apparently not widely used because the proportion of hypothetical calves (where $6 \% \mathrm{~F}$ was not avoided) is similar to the proportion of actual calves in the 6\% F category (Figs. 2 and 3). The assumption that semen use data can be used to predict the sire of next year's calves was validated by the correlation of 0.96 between semen use in 1999 and calves born per sire in 2000. The assumption that all progeny test bulls are used equally after their progeny test is obviously incorrect, but it does not affect the genetic composition of the herd in the short-term because the pedigrees of the selected bulls are similar to the pedigrees of average progeny test bulls.

Currently the prediction of the future cow population and their $\mathrm{F}$ is based on semen use information that was available up to March 2004 and calving data up to December 2004 and progeny test bulls that were born before 2004. Using this information, we are able to predict the genetic composition of cows that will be born up to 2009 (i.e. 5 years ahead). Over this timeframe the prediction should be good. However, if a change, for instance in mating policy occurs, the prediction could be updated every year by incorporating the new information and so should be reasonably accurate.

Based on current breeding practices, $\mathrm{F}$ is expected to increase at about $0.2-0.3 \%$ per year and warrants some attention in the breeding program. However, $\mathrm{F}$ values calculated from the recorded pedigree are still low and, perhaps because of this, the differences between the selection methods, shown in Tables III-V, do not seem to be very large. However, the trends are clear and differences would be large in populations with higher mean $\mathrm{F}$.

Methods to select bulls that take account of $\mathrm{F}$ can be classified according to whether they deal with long-term or short-term $\mathrm{F}$ and, in the latter case, 
whether they assume random or non-random mating. A method that focusses on short-term F under random mating is that of VanRaden and Smith [13] that characterised bulls by the expected mean $\mathrm{F}$ of their prospective progeny when randomly mated to cows born 3 years ago. Our selection criterion, APR adjusted for $\bar{F}$, uses the same $\bar{F}$ statistic as VanRaden and Smith [13]. Use of this criterion could be implemented in Australia by ADHIS publishing it on all bulls as a guide to dairy farmers. Similarly an AI stud, planning to import semen, could use this information to identify a bull that is less related to its target cow population. This can be done by using interbull EBV and by incorporating the potential bulls with their pedigree to the pedigree of the target population and calculating the $\mathrm{F}$ of their prospective progeny. This approach is suitable for a situation where breeding companies recruit bulls from anywhere in the world and aim to produce less inbred progeny.

If dairy farmers are prepared to non-randomly mate cows, the most effective way to decrease short-term F, and to maximise the total genetic merit of the next calf crop, is to select the best bulls from all the available bulls for each individual cow. This decreases the average $\mathrm{F}$ of the calves by about $1 \%$ in our examples. The recommendation to select bulls for individual cows based on APR and the F of the calf could be implemented in Australia by Herd Improvement Centres offering a service to their clients. In fact, some centres already offer a service that calculates the $\mathrm{F}$ of proposed matings and this could be easily upgraded to implement the method proposed here.

An AI company, selling semen in competition with others, would want to breed and progeny test bulls that will be attractive to their customers (dairy farmers). So, if dairy farmers mate randomly, and therefore select bulls using APR adj. for $\bar{F}$ based on the bulls' relationship to their cows when the bulls graduate, the AI company should also breed or select young bulls using this method. The method we have presented to predict the future cow population can be used by the AI company to predict the cow population at the time the bulls will complete their progeny test and hence select young bulls or their parents with the highest APR adjusted for $\bar{F}$ of future calves. However, if the AI company's customers mate non-randomly and select bulls based on APR adj. for F, then the AI company should select a team of bulls whose calves will be of high merit when used by dairy farmers according to method APR adj. for F. Again an AI company can implement this selection policy by predicting the cow population at the time the bulls will complete progeny test and, after testing many possible bull teams, selecting the team of bulls that maximise APR adjusted for F. This implies that the team of bulls includes a diversity of pedigrees to match the diversity of pedigree among the cow population. 
The selection methods discussed so far ignore long-term $\mathrm{F}$ which depends, in part, on the relationships among the bulls. Several bull selection methods $[4,8,10,16,18]$ are aimed at minimising long-term $\mathrm{F}$ by minimising $\mathrm{R}$ between selected animals. As expected the W\&G method gives the highest APR adjusted for R of the methods compared here. Surprisingly, method APR adj. for $\mathrm{F}$ also reduces $\mathrm{R}$ between bulls indirectly because cows with quite different pedigree exist in the population and therefore the method selects relatively unrelated bulls to mate to these cows. Method APR adjusted for $\bar{F}$ (i.e. assuming random mating) gives the worst long-term outcome as judged by APR adjusted for $\mathrm{R}$ because it compromises the APR of selected bulls without any reduction in $\mathrm{R}$.

Both long-term and short-term $\mathrm{F}$ could be considered by initially selecting a team of bulls using the W\&G method and later mating them selectively using method APR adj. for F. However, there seems to be little reason for an individual farmer or AI company competing in the market place to include long-term $\mathrm{F}$ in their selection decisions. Firstly, their decisions do not control long-term $\mathrm{F}$ because they control only part of the population and secondly, they would not capture any advantage over their competitors if long-term F did decrease. Fortunately, if they select to maximise APR adjusted for F of future calves, there is some tendency to reduce long-term $\mathrm{F}$ as well as short-term $\mathrm{F}$.

The exact cost of $\mathrm{F}$ is arguable so some people would prefer to restrict the rate of $\mathrm{F}$ to a preset maximum [10], which can be done by choosing a high enough cost of $\mathrm{F}$. There is also some merit in putting a cost factor on $\mathrm{F}$ when the objective is to maximise profit by minimising F. In a strictly commercial dairy enterprise the farmer may not be willing to forgo profitability for the sake of reducing F. Fortunately the bulls that are selected do not seem to be very sensitive to the cost of $\mathrm{F}$ that is assumed. In the W\&G method, increasing the cost of $\mathrm{F}$ is equivalent to decreasing the acceptable rate of increase in $\mathrm{F}$ and results in an increase in the number of bulls selected. For example, when Kearney et al. [8] decreased the rate of increase in F per generation from $2 \%$ to $0.2 \%$, the number of bulls required increased from 11 to 44 . However, in method APR adj. for F, increasing the cost of F only slowly increases the number of bulls selected and so only slightly reduces mean $\mathrm{R}$.

\section{CONCLUSION}

This study showed that information on the current cow population, semen use and progeny test bulls can be used to predict the future genetic composition of the dairy herd. The method is demonstrated using data from Australian 
Jersey and Holstein-Friesian cattle and predicts the genetic composition and $\mathrm{F}$ of the future cow population up to 6 years into the future. If current mating practices continue, $\mathrm{F}$ will increase by about $0.2 \%$ and $0.3 \%$ per year in $\mathrm{HF}$ and in Jersey animals, respectively, between 2002 and 2008. The bull selection method that selects the best bull for each cow, based on the calf EBV minus F depression reduces the average $\mathrm{F}$ of the calves by about a third to half even when the cost of $\mathrm{F}$ depression is as low as $3 \mathrm{APR} / \% \mathrm{~F}$. Currently dairy breeding decisions are controlled by many decision-makers each trying to maximise their own profit. The results from this study show that the rate of $\mathrm{F}$ can be close to optimal if their decisions are made correctly. When the best bull is selected for each cow, the mean APR adjusted for the average relationship between the bulls is nearly as high as with the method of Wray and Goddard [18] which aims to maximise this criterion.

\section{ACKNOWLEDGEMENTS}

Dairy Australia funded this work. We thank the ADHIS and the Australian Jersey Breeders Society for providing the data and Dr Boichard for using his software to calculate F. We thank Dr Kevin Beard for extracting the data and his valuable comments on the earlier version of this report.

\section{REFERENCES}

[1] ADHIS (Australian Dairy Herd Improvement Scheme), Australian Dairy Herd Improvement Report, ADHIS Pty Ltd. Level 6, 84 William Street, Melbourne, Vic 3000 Australia, 2005.

[2] AIPL, USDA, Subject: AIPL inbreeding coefficients for Holstein cows, http://aipl.arsusda.gov/dynamic/inbrd/current/HOt.html [consulted: 2 March 2005].

[3] Boichard D., PEDIG: A Fortran package for pedigree analysis suited for large population, CD-ROM 7th World Congress on Genetics Applied to Livestock Production, 2002, Communication no. 28-13.

[4] Brisbane J.R., Gibson J.P., Balancing selection response and rate of inbreeding by including genetic relationships in selection decisions, Theor. Appl. Genet. 91 (1995) 421-431.

[5] Canadian Dairy Network (CDN), 2004, Subject: Inbreeding, http://www.cdn.ca [consulted: 1 December 2004].

[6] Colleau J.-J., Moureaux S., Briend M., Bechu J., A method for dynamic management of genetic variability in dairy cattle, Genet. Sel. Evol. 36 (2004) 373-394.

[7] Goddard M.E., Smith C., Adjustment of sires' estimated breeding values for the prospective inbreeding impact on the breed, J. Dairy Sci. 73 (1990) (Suppl. 1) 223. 
[8] Kearney J.F., Wall E., Villanueva B., Coffey M.P., Inbreeding trends and application of optimized selection in the UK Holstein Population, J. Dairy Sci. 87 (2004) 3503-3509.

[9] Man W.Y.N., Inbreeding in Australian Holstein Friesian cattle, Ph.D. Thesis, The University of Sydney, Australia, 2004.

[10] Meuwissen T.H.E., Maximizing the response of selection with a predefined rate of inbreeding, J. Anim. Sci. 75 (1997) 1934-940.

[11] Smith L.A., Cassell B.G., Pearson R.E., The effects of inbreeding on the lifetime performance of dairy cattle, J. Dairy Sci. 81 (1998) 2729-2737.

[12] Thompson J.R, Everett R.W., Hammerschmidt N.L., Effects of inbreeding on production and survival in Holsteins, J. Dairy Sci. 83 (2000) 1856-1864.

[13] VanRaden P.M., Smith L.A., Selection and mating considering expected inbreeding of future progeny, J. Dairy Sci. 82 (1999) 2771-2778.

[14] Weigel K.A., Controlling inbreeding in modern breeding programs, J. Dairy Sci. 84 (2001) (Suppl.) E177-E184.

[15] Weigel K.A., Lin S.W., Use of computerized mate selection programs to control inbreeding of Holstein and Jersey cattle in the next generation, J. Dairy Sci. 83 (2000) 822-828.

[16] Weigel K. A., Lin S.W., Controlling inbreeding by constraining the average relationship between parents of young bulls entering AI progeny test programs, J. Dairy Sci. 85 (2002) 2376-2383.

[17] Wiggans R., VanRaden P.M., Zuurbier J., Calculation and use of inbreeding coefficients for genetic evaluation of United States dairy cattle, J. Dairy Sci. 78 (1995) 1584-1590.

[18] Wray N.R., Goddard M.E., Increasing long-term response to selection, Genet. Sel. Evol. 26 (1994) 431-451. 